\section{Tres medidas fundamentales para revitalizar el control del tabaquismo en las Américas}

\author{
Armando Peruga ${ }^{1}$
}

1 Organización Panamericana de la Salud, División de Promoción de la Salud, Programa de Salud Mental, Unidad de Tabaco, Alcohol y Drogas, Washington, D.C., EE.UU.
La epidemia de tabaquismo es un singular problema de salud pública cuya naturaleza y alcance son bien conocidos. Se sabe que el consumo de tabaco es el principal factor de carácter evitable que causa la muerte de más de un millón de personas en las Américas cada año. Se sabe, asimismo, que los productos del tabaco son adictivos y que casi siempre la adicción empieza en la adolescencia. Finalmente, también se sabe cuáles son las medidas necesarias para reducir el consumo de tabaco y cuáles son de mayor eficacia en función de los costos cuando se comparan con otras medidas sanitarias preventivas y con los devastadores costos humanos y económicos del consumo de tabaco. A pesar de esta apremiante situación, han sido insuficientes las medidas tomadas para desacelerar o hacer retroceder la epidemia.

Los países de las Américas, reunidos en el 43.er Consejo Directivo de la Organización Panamericana de la Salud (OPS), examinaron en septiembre de 2001 las medidas necesarias para revitalizar el control del tabaquismo en la Región. En esa ocasión se comprometieron a tomar medidas inmediatas para alcanzar las siguientes metas:

- que los niños crezcan en un ambiente sin incitaciones a fumar,

- que los adultos que quieren dejar de fumar reciban apoyo para hacerlo y

- que las personas que no fuman sean protegidas de los efectos perjudiciales de la exposición involuntaria al humo del tabaco.

\section{El Convenio Marco Internacional para la Lucha Antitabáquica}

La elaboración del Convenio Marco Internacional para la Lucha Antitabáquica (CMLAT) constituye una oportunidad singular de movilizar nuevas herramientas de salud pública para combatir el tabaquismo y alcanzar las metas establecidas para las Américas por el Consejo Directivo de la OPS. En noviembre de 2001 se reunió por tercera vez el Órgano Negociador Intergubernamental (ONI) del Convenio, cumpliéndose un año desde la primera reunión. El proceso de negociación se ha acometido con decisión por parte de los 193 países participantes, y la participación de los países de las Américas ha ido en aumento. A la última reunión del ONI asistieron 38 países de la Región. Sin embargo, los países de las Américas se enfrentan a varios retos para finalizar con éxito el complejo proceso de negociación del convenio.

Por una parte, es preciso desarrollar posiciones comunes que permitan aumentar el peso de la Región en el conjunto de la negociación y reducir el tiempo necesario para la discusión de propuestas. Con este fin, los países de América Latina se reunieron en Rio de Janeiro en noviembre de 2001 y alcanzaron consensos en algunos temas claves. Es necesario continuar este proceso y extenderlo a los demas países de la Región.

Por otra parte, convendría que la definición de las posturas de cada Gobierno obedeciese a un esfuerzo de coordinación intersectorial. Doce de los 19 países que participaron en la reunión de Rio de Janeiro manifestaron tener mecanismos de consulta interministerial para fijar la pos- 
tura del Gobierno. No obstante, solo dos - la República Dominicana y Brasil- tienen comisiones formales. En todos los países que asistieron a esta reunión y que carecen de mecanismos de consulta interministeriales, la posición ante el CMLAT la fija el Ministerio de Salud, mientras que entre los 12 países restantes la fijación de la posición está dirigida casi igualmente por la cancillería (7) y el Ministerio de Salud (5). Una de estas comisiones informales se compone de varias ONG (Panamá) y otra representa a la empresa tabacalera British American Tobacco (Nicaragua).

Por todo ello, el Consejo Directivo de la OPS alentó a los Estados Miembros a que "fortaleciesen la coordinación multisectorial en el ámbito nacional con el fin de adoptar posiciones nacionales coherentes con el CMLAT, respaldadas por esfuerzos para crear y adoptar planes nacionales integrales". Independientemente de lo que se acuerde en el CMLAT, el Consejo Directivo de OPS instó a los Estados Miembros a adoptar medidas para alcanzar las metas para las Américas señaladas anteriormente. Aunque estas metas son diferentes, se abordan de manera más eficaz mediante las mismas tres medidas de control: los aumentos de los impuestos sobre el tabaco, las prohibiciones de la promoción del tabaco, y las prohibiciones y restricciones del acto de fumar en lugares públicos.

El impuesto sobre el tabaco. La medida que por sí sola es más eficaz para reducir el consumo de tabaco es la política tributaria. Hay una estrecha relación entre el consumo per cápita de los productos de tabaco y el precio real. En América Latina y el Caribe, un aumento de 10\% del precio real de los productos de tabaco daría lugar a una disminución del consumo per cápita de cerca de $8 \%$. Esta sola medida daría lugar a que cuatro millones de fumadores dejaran de fumar, con lo que se salvaría un millón de vidas, al margen de la disuación de los fumadores potenciales o de alentar a los fumadores a que fumen menos.

Los impuestos son aun más eficaces en los grupos de bajos ingresos y los jóvenes, quienes tienen menos dinero disponible y son mucho más sensibles a los precios que la población en general. A un costo por año de vida ahorrado que oscila entre US\$ 4 y \$34 en la mayoría de los países de la Región, los impuestos se hallan entre las medidas de salud pública más eficaces en función de los costos, equivalentes a la vacunación de los niños y a la atención integrada a las enfermedades prevalentes de la infancia.

Algunos países, entre ellos Brasil y Chile, registran una incidencia tributaria del tabaco (la proporción del precio al menudeo correspondiente al impuesto) relativamente alta, de $70 \%$ o más. Sin embargo, aun en estos países, los productos de tabaco siguen siendo más asequibles que otros artículos de consumo. En Chile, una cajetilla de cigarrillos Marlboro cuesta $60 \%$ del precio de una hamburguesa Big Mac (dos productos consumidos por la clase media de estos países); en Colombia, menos de la mitad; y en Venezuela, un tercio del precio de la hamburguesa y la mitad de lo que cuesta un kilogramo de pan. Dicho de otra manera, los cigarrillos son más baratos que los alimentos.

Australia, Nueva Zelandia y Estados Unidos han comprobado que la repercusión de los impuestos sobre el tabaco puede fortalecerse mediante el uso de estos ingresos tributarios para financiar medidas integrales de control del tabaquismo. En Estados Unidos, los estados que han implantado programas de control financiados por impuestos sobre el tabaco han logrado disminuciones del consumo mucho mayores que el promedio nacional. 
El contrabando a menudo se usa como argumento para que los gobiernos no aumenten los impuestos sobre el tabaco. Sin embargo, el principal factor predictivo del contrabando no lo constituyen las diferenciales tributarias, sino el grado de corrupción en una jurisdicción dada. De todos modos, existen métodos eficaces para controlar el contrabando y los gobiernos deben considerar tales controles como parte integrante de un programa eficaz para el control del consumo de tabaco.

Las restricciones de la promoción del tabaco. La promoción del tabaco, incluidas la publicidad directa, la publicidad de marcas comerciales del tabaco mediante el patrocinio de actos culturales y deportivos, otros bienes y servicios, y los obsequios, influye en el consumo del tabaco. La promoción también es un factor importante que contribuye al inicio del tabaquismo. Las pruebas indican que las restricciones totales del tabaco reducen el consumo; en cambio, las restricciones parciales tienen poca o ninguna repercusión sobre el consumo. En un artículo de este número de la Revista Panamericana de Salud Pública, Saloojee y Hammond hacen una revisión pormenorizada de los efectos de la publicidad sobre el consumo de tabaco y analizan las soluciones científicas existentes y el efecto de las restricciones integrales (prohibición completa o casi completa) de la promoción.

Mientras que algunos países han fortalecido sus controles reglamentarios de la promoción y consumo del tabaco, es probable que estos cambios tengan una repercusión mínima porque no son suficientemente integrales y contienen lagunas jurídicas que menoscaban su intención. Solo Brasil, Canadá y Cuba tienen restricciones suficientemente amplias como para tener algún impacto.

En virtud de las pruebas científicas existentes, el Consejo Directivo de la OPS ha instado a los Estados Miembros a que "prevengan el inicio del consumo de tabaco y promuevan su cesación mediante la aplicación y el cumplimiento de medidas eficaces en función de los costos para reducir el consumo de tabaco, entre ellas la fijación de impuestos al tabaco a niveles que disminuyan el consumo y la supresión progresiva de la promoción de los productos de tabaco, en conformidad con las constituciones nacionales."

Las restricciones del acto de fumar. Las restricciones del acto de fumar en los lugares públicos y de trabajo reducen tanto la prevalencia del tabaquismo como la cantidad de tabaco consumida por cada fumador. Además, dichas restricciones son las manifestaciones más visibles de las normas cambiantes de una sociedad con respecto al consumo de tabaco. Los jóvenes que se crían en espacios sin tabaco tienen mayores probabilidades de considerar el consumo de tabaco como algo insólito y socialmente inadmisible. Si se prohíbe el acto de fumar en los entornos sociales que atraen a muchos adolescentes, el tabaquismo deja de ser visto como "rito iniciático" para pasar a la adultez. Por este motivo, los espacios sin humo de tabaco son una herramienta crucial de mercadeo social para el control del tabaquismo.

La exposición de cónyuges e hijos al humo de tabaco en el ambiente doméstico es motivo de gran preocupación. En Argentina, 70\% de los niños en edad escolar están expuestos involuntariamente al humo de tabaco en el hogar. La exposición es de $60 \%$ en Chile y Suriname, y de casi $50 \%$ en Bolivia, México y Venezuela. En México, $61 \%$ de las mujeres que no fuman están expuestas al humo de tabaco en el ambiente, a diferencia de $39 \%$ de los hombres que no fuman. Además de causar asma, bronquitis, neumonía e infecciones del oído en los niños y cáncer del pulmón y car- 
diopatía en los adultos, el aire contaminado con humo de tabaco tiene una repercusión adversa sobre la salud perinatal. El tabaquismo de la madre o la exposición in utero al humo de tabaco ambiental aumenta enormemente el riesgo de aborto espontáneo, complicaciones del parto, bajo peso al nacer y problemas del desarrollo. El humo de tabaco en el ambiente se asocia con cerca de $40 \%$ de los casos de muerte súbita del lactante.

En vista de la situación, el Consejo Directivo de la OPS pidió que se "proteja a todos los no fumadores, en particular los niños y las mujeres embarazadas, de la exposición al humo de tabaco en el ambiente mediante la prohibición inmediata del acto de fumar en los edificios del gobierno, establecimientos de asistencia sanitaria e instituciones educativas, y mediante la creación, lo antes posible, de entornos sin humo de tabaco en los centros de trabajo y lugares públicos, reconociendo que los entornos sin humo de tabaco también promueven la cesación del consumo de tabaco y previenen su inicio".

Repercusión sobre la salud pública. De las medidas propuestas, aquellas que no redundan en un aumento del precio de los productos darían lugar a disminuciones de la prevalencia de entre $2 \%$ y $10 \%$ si los fumadores actuales dejaran el hábito. Esto se traduciría en 2 a 10 millones de fumadores menos y en 0,5 a 2 millones menos de defunciones relacionadas con el tabaquismo en América Latina y el Caribe. Si estas medidas se sumaran a un aumento del precio de solo $10 \%$, se podrían prevenir entre 1,5 y 3 millones de defunciones porque un mayor número de las personas que fuman actualmente dejarían de fumar. En realidad, se salvarían más vidas debido a que menos personas iniciarían el hábito y las que ya fuman reducirían el consumo.

Si bien los beneficios para la salud pública que aportan las medidas de control del consumo de tabaco deberían ser razón suficiente para adoptarlas, muchos gobiernos han expresado inquietud en cuanto al efecto de la reducción del consumo de tabaco en la economía. Afortunadamente, las metas del control del consumo de tabaco y el bienestar económico son muy compatibles.

Numerosos estudios han revelado que la reducción o eliminación del consumo de tabaco no tendrá ninguna repercusión económica negativa para la gran mayoría de los países, y en algunos casos las consecuencias serán beneficiosas. Cuando las personas no gastan dinero en cigarrillos, lo gastan en otras cosas, la mayoría de las cuales imponen costos sociales mucho menores que el tabaco.

Sabemos que el tabaquismo causa graves problemas de salud, sabemos cuáles son las soluciones que funcionan y contamos con el compromiso de los Gobiernos de las Américas reunidos en el Consejo Directivo de la OPS para tomar medidas inmediatas y eficaces. También sabemos que el trabajo será arduo, pero hay numerosos ejemplos de que es posible lograr un impacto importante si todos los sectores de la sociedad civil, del gobierno y de la comunidad internacional preocupados por el problema del tabaquismo unen sus fuerzas. 